Article

\title{
Serum Vitamin Levels and Their Relationships with Other Biomarkers in Korean Breast Cancer Patients
}

\author{
Jee Ah Kim ${ }^{1}\left(\mathbb{D}\right.$, Rihwa Choi ${ }^{1,2}{ }^{\mathbb{D}}$, Hojeong Won ${ }^{3}$, Seonwoo Kim ${ }^{3}$, Hee Jun Choi ${ }^{4}$, Jai Min Ryu ${ }^{5}$, \\ Se Kyung Lee ${ }^{5}$, Jonghan $\mathrm{Yu}^{5}$, Seok Won Kim ${ }^{5}$, Jeong Eon Lee ${ }^{5, *}$ and Soo-Youn Lee ${ }^{1, *(\mathbb{D})}$ \\ 1 Department of Laboratory Medicine and Genetics, Samsung Medical Center, Sungkyunkwan University \\ School of Medicine, 81 Irwon-ro, Gangnam-gu, Seoul 06351, Korea; jeeah89.kim@samsung.com (J.A.K.); \\ pirate0720@naver.com (R.C.) \\ 2 Department of Laboratory Medicine, Green Cross Laboratories, Gyeonggi, Yongin 16924, Korea \\ 3 Statistics and Data Center, Research Institute for Future Medicine, Samsung Medical Center, \\ Seoul 06351, Korea; hojeong.won@sbri.co.kr (H.W.); seonwoo.kim@samsung.com (S.K.) \\ 4 Department of Surgery, Samsung Changwon Hospital, Sungkyunkwan University School of Medicine, \\ Changwon 51353, Korea; heejun1.choi@samsung.com \\ 5 Division of Breast Surgery, Department of Surgery, Samsung Medical Center, Sungkyunkwan University \\ School of Medicine, 81 Irwon-ro, Gangnam-gu, Seoul 06351, Korea; jaimin.ryu@samsung.com (J.M.R.); \\ sekyung.lee@samsung.com (S.K.L.); lymbics@hanmail.net (J.Y.); seokwon1.kim@samsung.com (S.W.K.) \\ * Correspondence: jeongeon.lee@samsung.com (J.E.L.); suddenbz@skku.edu (S.-Y.L.); \\ Tel.: +82-2-3410-3479 (J.E.L.); +82-2-3410-1834 (S.-Y.L.); Fax: +82-2-3410-6982 (J.E.L.); +82-2-3410-2719 (S.-Y.L.)
}

Received: 19 August 2020; Accepted: 12 September 2020; Published: 16 September 2020

\begin{abstract}
Numerous studies have shown that vitamins reduce the risk of cancers, but the relationship between serum vitamin levels and breast cancer is still controversial. In this study, we evaluated serum levels of vitamins in Korean patients with benign breast disease or breast cancer and investigated their associations with clinical and laboratory parameters. Concentrations of vitamin A, D, and E, together with homocysteine and methylmalonic acid as biomarkers of vitamin B12 deficiency, were measured by high-performance liquid chromatography (HPLC) or liquid chromatography with tandem mass spectrometry (LC-MS/MS) in the serum of 104 breast cancer patients, 62 benign breast disease patients, and 75 healthy Korean females. We further assessed possible associations between vitamin levels and breast cancer subtypes, the presence of lymph node metastasis, and tumor stages. Serum concentrations of vitamins A and E were significantly lower in breast cancer patients and in benign breast disease patients than in healthy controls. Severe vitamin $\mathrm{D}$ deficiency was more prevalent in breast cancer patients than in healthy controls. Vitamin D level was significantly lower in breast cancer patients with estrogen receptor-negative or triple-negative subtypes than in those with other subtypes. Further research with a larger study population is required to elucidate the role of vitamins in breast cancer.
\end{abstract}

Keywords: vitamin; benign breast disease; breast cancer; Korea

\section{Introduction}

Environmental factors such as radiation, pollution, infection, and diet contribute significantly to the onset of cancer. Numerous studies have identified the positive effects of dietary patterns on reducing certain types of cancer [1]. Through epidemiological studies, a role for nutrients in cancer development has been suggested and is associated to the antioxidant properties. Certain nutrients affect DNA repair, inflammation, and levels of endogenous hormones and growth factors by regulating gene expression [2]. 
Vitamins are required by various physiological and biochemical mechanisms of the body and are known to have antioxidant properties and improve the immune response [3]. A number of studies have shown that low intake and low serum vitamin levels have a strong association with a higher risk of cancer [4-7]. Over the past two decades, researchers have focused on the roles of vitamin in breast cancer etiology [8-10]. Some studies have reported a relationship between dietary pattern and reduced risk of postmenopausal breast cancer [11,12]. However, results among studies are often conflicting and much remains unknown about the relationship between vitamins and breast cancer. In addition, because benign breast disease is associated with increased breast cancer risk $[13,14]$, there are efforts to identify the relationship between serum vitamin levels and benign breast disease, but results are inconsistent and inconclusive $[15,16]$. Possible reasons for inconsistencies among studies may be the use of different analytical methods to measure various metabolites of the vitamins of interest, and enrollment of participants from populations of different ethnicities.

Dietary factors may have different impacts according to breast cancer subtype, but only vitamin $\mathrm{D}$ has been investigated in this context. As specific nutrients and vitamins may be more particularly related to the promotion of, or protection from, certain types of breast cancer, stratification of breast cancer by specific tumor characteristics such as tumor stage and molecular classification needs to be considered $[17,18]$.

In this study, we evaluated serum levels of multiple vitamins in Korean female patients with benign breast disease and patients with breast cancer and investigated their relationships with clinical/laboratory parameters. We further evaluated possible associations between serum concentrations of vitamin markers and breast cancer subtypes, the presence of lymph node metastasis, and tumor stages, as these phenotypes have significant implications for prognosis and the effectiveness of targeted therapies.

\section{Materials and Methods}

\subsection{Study Population}

We performed a case-control study comprising 104 adult female patients histopathologically diagnosed with breast cancer, 62 female patients with a histopathological diagnosis of benign breast disease, including fibrocystic change or fibroadenoma, and 75 healthy Korean females. All patients with breast cancer or breast disease were diagnosed at Samsung Medical Center (Seoul, Korea), a tertiary care hospital, between March 2015 and March 2019. Patients with any tumor other than primary breast benign or malignant tumor, patients with malabsorption, patients with recurrent infections, patients with inflammatory diseases, or patients with impaired liver or kidney function (total bilirubin $>2.5 \mathrm{mg} / \mathrm{dL}$, aspartate aminotransferase (AST) or alanine aminotransferase (ALT) $>3$ times the upper limit of the reference interval, alkaline phosphatase (ALP) $>5$ times the upper limit of the reference interval, serum creatinine $>1.8 \mathrm{mg} / \mathrm{dL}$ ) were excluded. The 75 control female subjects with no benign breast disease or breast cancer were recruited from among individuals who visited a health promotion center for a medical checkup who had no clinical symptoms or signs of breast disease.

The study was approved by the Institutional Review Board of Samsung Medical Center (IRB No: SMC-2016-07-129). Demographic and clinical characteristics including age, body mass index (BMI), menopausal status and serum biochemistry test results (total protein, albumin, AST, ALT, ALP, high density lipoprotein (HDL), low density lipoprotein (LDL), total cholesterol) were collected from electronic medical records. Individuals were classified as overweight if $23 \leq \mathrm{BMI}<25 \mathrm{~kg} / \mathrm{m}^{2}$ and as obese if BMI $\geq 25 \mathrm{~kg} / \mathrm{m}^{2}$ in accordance with World Health Organization (WHO) guidelines for Asian populations [19]. Information obtained from surgery about breast cancer subtypes such as estrogen receptor (ER), progesterone receptor (PR), and human epidermal growth factor receptor 2 (HER2) presence or absence was reviewed retrospectively through electronic medical records, in addition to tumor stage and the presence of lymph node metastasis. 


\subsection{Analytical Procedures}

Blood samples to determine vitamin levels were collected from patients who were fasted during the first visit before any treatment. Serum levels of vitamin A and E were measured by high-performance liquid chromatography (HPLC). Serum vitamin D $(25(\mathrm{OH}) \mathrm{D})$ level was determined as the sum of serum 25-hydroxyvitamin D2 $\left(25(\mathrm{OH}) \mathrm{D}_{2}\right)$ and 25-hydroxyvitamin $\mathrm{D} 3\left(25(\mathrm{OH}) \mathrm{D}_{3}\right)$ levels. Liquid chromatography with tandem mass spectrometry (LC-MS/MS) was used to measure serum $25(\mathrm{OH}) \mathrm{D}_{2}$ and $25(\mathrm{OH}) \mathrm{D}_{3}$ levels (Figure $\mathrm{S} 1$ ). Serum homocysteine and methylmalonic acid levels, as indicators of vitamin B12 status, were measured by LC-MS/MS. All serum levels of vitamin markers were measured using methods reported by Oh et al. [20]. The accuracy of serum vitamin A, D, E, and B12 indicator measurements were verified by regularly participating in external quality assurance programs including the Proficiency Testing/Quality Management program of the College of American Pathologists (CAP) survey and the Vitamin D External Quality Assessment Scheme (DEQAS). Coefficients of variation for intra- and inter-assay were $<10 \%$ in all assays, indicating good repeatability. To evaluate biochemical status, serum chemistry parameters such as total protein, albumin, AST, ALT, ALP, HDL, LDL, and total cholesterol were measured using a Roche cobas c702 clinical analyzer (Roche Diagnostics Corp., Indianapolis, IN, USA).

Vitamin deficiencies were defined as described in previous reports: vitamin A deficiency as $<1.05 \mu \mathrm{mol} / \mathrm{L}$, vitamin E deficiency as $<11.6 \mu \mathrm{mol} / \mathrm{L}$, and vitamin B12 deficiency as a methylmalonic acid concentration $>300 \mathrm{nmol} / \mathrm{L}$ or a homocysteine concentration $>15 \mu \mathrm{mol} / \mathrm{L}$ [20]. Vitamin D deficiency was defined as a serum $25(\mathrm{OH}) \mathrm{D}$ concentration $<20 \mathrm{ng} / \mathrm{mL}$ and severe vitamin D deficiency was defined as a serum $25(\mathrm{OH}) \mathrm{D}$ concentration $<10 \mathrm{ng} / \mathrm{mL}$ [21].

\subsection{Statistical Analysis}

SPSS software v25.0 (SPSS Inc. 233 S. Chicago, IL, USA) was used to analyze data. Continuous variables are presented as medians and interquartile ranges (IQRs). p-values less than 0.05 were considered to be statistically significant. We used the Kruskal-Wallis test, ANOVA, and Tukey's test on ranked data to assess the significance of differences in serum levels of vitamin status markers and vitamin deficiencies among breast cancer patients, benign breast disease patients, and healthy controls. Odds ratios and 95\% confidence intervals (CI) were calculated to estimate relative risks for the exposure variables directly of interest as well as potential confounding variables. Potential confounding effects of age, menopausal state, BMI, total protein, albumin, AST, ALT, ALP, and total cholesterol were adjusted for in multivariate logistic regression analysis. Wilcoxon rank sum test and Kruskal-Wallis test were used to analyze the significance of differences in breast cancer subtypes. To evaluate the associations among serum levels of vitamin status markers, demographic data, and biochemical results, Spearman's correlations were calculated. According to the classification system which Hebel et al. proposed, $r$ values below 0.2 indicate a negligible correlation, $r$ values between 0.2 and 0.5 indicate a weak positive correlation, $r$ values between 0.5 and 0.8 indicate a moderate positive correlation, and $r$ values between 0.8 and 1.0 indicate a strong positive correlation [22].

\section{Results}

\subsection{General Characteristics of the Study Population}

This study comprised 75 healthy controls, 62 patients with benign breast disease, and 104 patients with breast cancer. The general characteristics of the study participants are summarized in Table 1. Patients with breast cancer had a higher BMI than the other groups $(p=0.0059)$ and had a high prevalence of obesity compared to healthy controls and patients with benign breast disease $(p=0.0053)$. Breast cancer patients, as well as benign breast disease patients, had significantly lower concentrations of total cholesterol than healthy controls $(p=0.0004)$. Among the 104 breast cancer patients, 92 (88.5\%) had ER-positive breast cancer, 85 (81.7\%) had PR-positive breast cancer, 
28 (26.9\%) had HER2-positive/equivocal breast cancer, while six (5.8\%) had triple negative breast cancer. Sixteen $(15.4 \%)$ patients with breast cancer exhibited lymph node metastasis.

Table 1. General characteristics of the study population.

\begin{tabular}{|c|c|c|c|c|c|}
\hline & & $\begin{array}{l}\text { Healthy Controls } \\
\qquad(n=75)\end{array}$ & $\begin{array}{c}\text { Benign Breast } \\
\text { Disease Patients } \\
\quad(n=62)\end{array}$ & $\begin{array}{c}\text { Breast Cancer } \\
\text { Patients }(n=104)\end{array}$ & $p$-Values ${ }^{b}$ \\
\hline \multicolumn{6}{|c|}{ Demographic characteristics } \\
\hline \multicolumn{2}{|c|}{ Age (years) ${ }^{a}$} & $49(39-54)$ & $43(36-50)$ & $49(44-55)$ & $0.001^{c}$ \\
\hline \multirow{2}{*}{ Menopausal state } & Pre-menopause, N (\%) & $44(58.7 \%)$ & $48(77.4 \%)$ & $65(62.5 \%)$ & \multirow{2}{*}{0.0551} \\
\hline & Post-menopause, N (\%) & $31(41.3 \%)$ & $14(22.6 \%)$ & $39(37.5 \%)$ & \\
\hline \multicolumn{2}{|c|}{ Body mass index $\left(\mathrm{kg} / \mathrm{m}^{2}\right)^{a}$} & $22(20-24)$ & $22(20-24)$ & $23(21-25)$ & 0.0059 \\
\hline & $\mathrm{BMI}<23, \mathrm{~N}(\%)$ & $47(62.7 \%)$ & $43(69.4 \%)$ & $50(48.1 \%)$ & \multirow{3}{*}{0.0053} \\
\hline & $23 \leq \mathrm{BMI}<25, \mathrm{~N}(\%)$ & $20(26.7 \%)$ & $14(22.6 \%)$ & $29(27.9 \%)$ & \\
\hline & $25 \leq \mathrm{BMI}, \mathrm{N}(\%)$ & $8(10.7 \%)$ & $5(8.1 \%)$ & $25(24.0 \%)$ & \\
\hline \multicolumn{6}{|c|}{ Serum chemistry results ${ }^{a}$} \\
\hline \multicolumn{2}{|c|}{ Total protein $(\mathrm{g} / \mathrm{dL})$} & $7.1(6.9-7.5)$ & $7.3(6.8-7.5)$ & $7.2(6.9-7.4)$ & 0.9314 \\
\hline \multicolumn{2}{|c|}{ Albumin $(\mathrm{g} / \mathrm{dL})$} & $4.4(4.3-4.6)$ & $4.5(4.3-4.7)$ & $4.4(4.3-4.6)$ & 0.0549 \\
\hline \multicolumn{2}{|c|}{ AST (U/L) } & $19(16-22)$ & $19(16-22)$ & $17(15-21)$ & 0.1009 \\
\hline \multicolumn{2}{|c|}{ ALT (U/L) } & $15(11-20)$ & $14(11-22)$ & $14(12-18)$ & 0.8592 \\
\hline \multicolumn{2}{|c|}{$\operatorname{ALP}(\mathrm{U} / \mathrm{L})$} & $55(44-68)$ & $54(41-69)$ & $56(46-68)$ & 0.6366 \\
\hline \multicolumn{2}{|c|}{ HDL (mg/dL) } & $63(52-75)$ & $64(55-72)$ & $63(51-74)$ & 0.8118 \\
\hline \multicolumn{2}{|c|}{ LDL (mg/dL) } & $116(97-136)$ & $100(89-128)$ & $108(90-137)$ & 0.4161 \\
\hline \multicolumn{2}{|c|}{ Total cholesterol (mg/dL) } & $190(174-215)$ & $167(155-191)$ & $178(160-206)$ & $0.0004^{c}$ \\
\hline
\end{tabular}

Abbreviations: BMI, body mass index; AST, aspartate aminotransferase; ALT, alanine aminotransferase; ALP, alkaline phosphatase; HDL, high density lipoprotein; LDL, low density lipoprotein. ${ }^{\text {a }}$ Results are presented as medians (interquartile ranges) or numbers $(\%) .{ }^{\mathrm{b}} p$-values based on Kruskal-Wallis test for nonparametric data and

${ }^{c}$ ANOVA for parametric data.

\subsection{Vitamin Status in the Study Population}

Serum levels of vitamins and vitamin biomarkers in the study populations are presented in Table 2 and Figure 1. Serum concentrations of vitamins A and $\mathrm{E}$ in patients with breast cancer and in patients with benign breast disease were significantly lower than in healthy controls, respectively $(p<0.001)$. However, serum concentrations of vitamin $\mathrm{D}$, homocysteine, and methylmalonic acid were not statistically different between groups. There were no statistically significant differences among serum vitamin levels between patients with breast cancer and patients with benign breast disease. The odds of having benign or malignant breast tumors were estimated through multivariable-adjusted logistic regression models (Table 3). Vitamin A was associated with a lower risk of both benign breast disease (odds ratio $(\mathrm{OR})=0.13,95 \% \mathrm{CI}=0.04-0.36, p=0.0001)$ and breast cancer $(\mathrm{OR}=0.20$, $95 \% \mathrm{CI}=0.08-0.48, p=0.0004)$. Vitamins $\mathrm{D}, \mathrm{E}$, methylmalonic acid, and homocysteine showed no significant associations with either benign breast disease or breast cancer.

Table 2. Serum concentrations of vitamins and vitamin B12 indicators in the study population.

\begin{tabular}{|c|c|c|c|c|c|c|c|}
\hline & $\begin{array}{l}\text { Healthy Controls } \\
\quad(n=75)\end{array}$ & $\begin{array}{c}\text { Benign Breast } \\
\text { Disease Patients } \\
(n=62)\end{array}$ & $\begin{array}{c}\text { Breast Cancer } \\
\text { Patients }(n=104)\end{array}$ & $p$-Values ${ }^{\mathrm{b}}$ & $\begin{array}{l}\text { Healthy Controls vs. } \\
\text { Benign Breast } \\
\text { Disease Patients }\end{array}$ & $\begin{array}{l}\text { Healthy Controls } \\
\text { vs. Breast Cancer } \\
\text { Patients }\end{array}$ & $\begin{array}{c}\text { Benign Breast } \\
\text { Disease Patients } \\
\text { vs. Breast Cancer } \\
\text { Patients }\end{array}$ \\
\hline \multicolumn{2}{|c|}{ Serum Vitamin Concentrations ${ }^{a}$} & & & & $p$-Values ${ }^{\mathrm{c}}$ & $p$-Values ${ }^{\mathrm{c}}$ & $p$-Values ${ }^{\mathrm{c}}$ \\
\hline $\begin{array}{c}\text { Vitamin A } \\
(\mu \mathrm{mol} / \mathrm{L})\end{array}$ & $\begin{array}{c}1.76 \\
(1.52-2.16)\end{array}$ & $\begin{array}{c}1.35 \\
(1.16-1.60)\end{array}$ & $\begin{array}{c}1.45 \\
(1.18-1.70)\end{array}$ & $<0.0001$ & $<0.0001$ & $<0.0001$ & 0.4354 \\
\hline Vitamin D (ng/mL) & $\begin{array}{c}18.0 \\
(12.2-23.5)\end{array}$ & $\begin{array}{c}15.8 \\
(11.0-20.1)\end{array}$ & $\begin{array}{c}14.7 \\
(9.4-22.2)\end{array}$ & 0.0515 & 0.1478 & 0.0546 & 0.9812 \\
\hline $\begin{array}{l}\text { Methylmalonic } \\
\text { acid (nmol/L) }\end{array}$ & $\begin{array}{c}111.3 \\
(78.5-170.4)\end{array}$ & $\begin{array}{c}112.5 \\
(80.9-165.1)\end{array}$ & $\begin{array}{c}96.4 \\
(73.5-127.3)\end{array}$ & 0.0378 & 0.9923 & 0.0812 & 0.0799 \\
\hline $\begin{array}{l}\text { Homocysteine } \\
(\mu \mathrm{mol} / \mathrm{L})\end{array}$ & $\begin{array}{c}8.0 \\
(6.9-9.5)\end{array}$ & $\begin{array}{c}8.2 \\
(6.7-9.9)\end{array}$ & $\begin{array}{c}7.8 \\
(6.6-9.4)\end{array}$ & 0.8198 & 0.9913 & 0.824 & 0.9052 \\
\hline
\end{tabular}

${ }^{\mathrm{a}}$ Results are presented as medians (interquartile ranges). ${ }^{\mathrm{b}} p$-values are from Kruskal-Wallis test and ${ }^{\mathrm{c}}$ Tukey's test using ranks. 

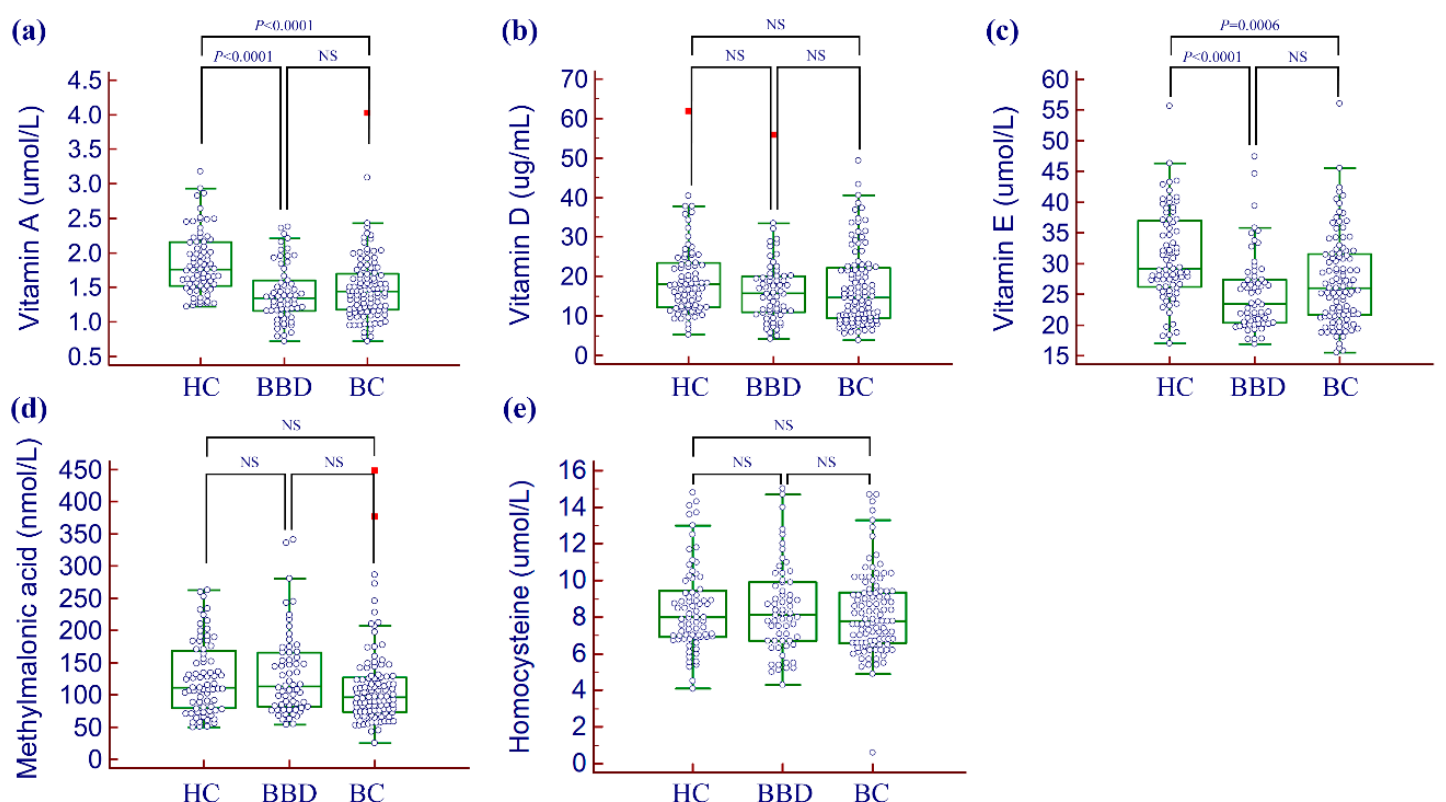

Figure 1. Comparison of vitamins and vitamin B12 status indicators between healthy controls, patients with benign breast disease, and patients with breast cancer. (a) vitamin $\mathrm{A}$, (b) vitamin $\mathrm{D}$, (c) vitamin $\mathrm{E}$, (d) methylmalonic acid, and (e) homocysteine. Abbreviations: NS, not significant; HC, healthy controls; $\mathrm{BBD}$, patients with benign breast disease; BC, patients with breast cancer.

Table 3. Crude and adjusted estimated odds ratios for breast cancer and benign breast disease (and 95\% confidence intervals) associated with serum levels of vitamin status markers (multivariate logistic regression model).

\begin{tabular}{|c|c|c|c|c|}
\hline & & $\begin{array}{l}\text { Healthy Controls } \\
\quad(n=75)\end{array}$ & $\begin{array}{c}\text { Benign Breast Disease } \\
\text { Patients }(n=62)\end{array}$ & $\begin{array}{c}\text { Breast Cancer } \\
\text { Patients }(n=104)\end{array}$ \\
\hline \multirow{4}{*}{ Vitamin A $(\mu \mathrm{mol} / \mathrm{L})$} & OR $(95 \% \mathrm{CI})$ & 1.00 & $0.17(0.07-0.45)$ & $0.26(0.12-0.57)$ \\
\hline & $p$-values & & $<0.0001$ & $<0.0001$ \\
\hline & OR $(95 \% \text { CI })^{a}$ & 1.00 & $0.13(0.04-0.36)$ & $0.20(0.08-0.48)$ \\
\hline & $p$-values & & 0.0001 & 0.0004 \\
\hline \multirow{4}{*}{ Vitamin D (ng/mL) } & OR $(95 \%$ CI $)$ & 1.00 & $0.99(0.95-1.03)$ & $0.99(0.96-1.03)$ \\
\hline & $p$-values & & 0.1478 & 0.0546 \\
\hline & OR $(95 \% \text { CI })^{a}$ & 1.00 & $0.98(0.94-1.02)$ & $0.99(0.95-1.02)$ \\
\hline & $p$-values & & 0.3441 & 0.4358 \\
\hline \multirow{4}{*}{ Vitamin E ( $\mu \mathrm{mol} / \mathrm{L})$} & OR $(95 \%$ CI $)$ & 1.00 & $0.92(0.87-0.98)$ & $0.96(0.92-1.01)$ \\
\hline & $p$-values & & $<0.0001$ & 0.0006 \\
\hline & OR $(95 \% \text { CI })^{a}$ & 1.00 & $0.97(0.90-1.05)$ & $0.96(0.91-1.02)$ \\
\hline & $p$-values & & 0.4428 & 0.1867 \\
\hline \multirow{4}{*}{$\begin{array}{l}\text { Methylmalonic } \\
\text { acid (nmol/L) }\end{array}$} & OR $(95 \%$ CI $)$ & 1.00 & $1.00(1.00-1.01)$ & $1.00(0.99-1.00)$ \\
\hline & $p$-values & & 0.9923 & 0.0812 \\
\hline & OR $(95 \% \text { CI })^{a}$ & 1.00 & $1.01(1.00-1.01)$ & $1.00(0.99-1.01)$ \\
\hline & $p$-values & & 0.1169 & 0.6642 \\
\hline \multirow{4}{*}{$\begin{array}{l}\text { Homocysteine } \\
\quad(\mu \mathrm{mol} / \mathrm{L})\end{array}$} & OR $(95 \% \mathrm{CI})$ & 1.00 & $1.01(0.85-1.20)$ & $1.01(0.87-1.16)$ \\
\hline & $p$-values & & 0.9913 & 0.8240 \\
\hline & OR $(95 \% \text { CI })^{a}$ & 1.00 & $1.03(0.86-1.23)$ & $0.99(0.84-1.17)$ \\
\hline & $p$-values & & 0.7615 & 0.8916 \\
\hline
\end{tabular}

Abbreviations: OR, odds ratio; 95\% CI, 95\% confidence interval. ${ }^{a}$ Adjusted for age, menopausal state, BMI, total protein, albumin, AST, ALT, ALP, and total cholesterol.

Vitamin A deficiency $(<1.05 \mu \mathrm{mol} / \mathrm{L})$ was observed in 13 patients with breast cancer $(12.5 \%)$, and in 11 patients with benign breast disease $(17.7 \%)$, but in none of the healthy controls. Severe vitamin D deficiency $(<10 \mathrm{ng} / \mathrm{mL})$ was significantly more prevalent in patients with breast cancer than in patients with benign breast disease and in healthy controls (29/104 (27.9\%) in breast cancer patients 
vs. $12 / 62(19.4 \%)$ in benign breast disease patients vs. $7 / 75(9.3 \%)$ in healthy controls, $p=0.0092)$. Vitamin B12 deficiency (methylmalonic acid $>300 \mathrm{nmol} / \mathrm{L}$ or homocysteine $>15 \mu \mathrm{mol} / \mathrm{L}$ ) was observed in two patients with breast cancer $(1.9 \%)$, and in two patients with benign breast disease (3.2\%), but not in any healthy controls. No patients had vitamin E deficiency $(<11.6 \mu \mathrm{mol} / \mathrm{L})$.

Serum levels of vitamins were compared among breast cancer patients with or without ER, PR, HER2, and triple-negative breast cancer which were negative for all of three receptors (Table 4). Concentrations of vitamin D were significantly lower in ER-negative breast cancer patients than in ER-positive breast cancer patients $(p=0.0233)$. In women with triple-negative breast cancer, concentrations of vitamin D were significantly lower $(p=0.0266)$ and concentrations of methylmalonic acid was significantly higher $(p=0.0384)$ than in women with breast cancer that expresses one or more of the hormone receptors. Serum levels of vitamins were compared among breast cancer patients with and without nodal metastasis and different stages of breast cancer, but no significant differences were observed.

Table 4. Subgroup analyses of vitamin levels in 104 breast cancer patients ${ }^{\text {a }}$.

\begin{tabular}{|c|c|c|c|c|c|c|}
\hline & & $\begin{array}{c}\text { Vitamin A } \\
(\mu \mathrm{mol} / \mathrm{L})\end{array}$ & $\begin{array}{c}\text { Vitamin D } \\
(\mathrm{ng} / \mathrm{mL})\end{array}$ & $\begin{array}{c}\text { Vitamin E } \\
(\mu \mathrm{mol} / \mathrm{L})\end{array}$ & $\begin{array}{c}\text { Methylmalonic } \\
\text { Acid ( } \mu \mathrm{mol} / \mathrm{L})\end{array}$ & $\begin{array}{c}\text { Homocysteine } \\
(\mu \mathrm{mol} / \mathrm{L})\end{array}$ \\
\hline \multirow{3}{*}{ ER } & Negative $(n=12)$ & $\begin{array}{c}1.34 \\
(1.16-1.67)\end{array}$ & $\begin{array}{c}8.5 \\
(7.1-15.8)\end{array}$ & $\begin{array}{c}27.3 \\
(22.3-29.0)\end{array}$ & $\begin{array}{c}104.8 \\
(85.8-163.4)\end{array}$ & $\begin{array}{c}8.1 \\
(6.5-9.6)\end{array}$ \\
\hline & Positive $(n=92)$ & $\begin{array}{c}1.45 \\
(1.19-1.72)\end{array}$ & $\begin{array}{c}15.0 \\
(10.1-22.7)\end{array}$ & $\begin{array}{c}25.8 \\
(21.6-32.0)\end{array}$ & $\begin{array}{c}95.4 \\
(73.0-124.5)\end{array}$ & $\begin{array}{c}7.8 \\
(6.7-9.4)\end{array}$ \\
\hline & $p$-values ${ }^{\mathrm{b}}$ & 0.6145 & 0.0233 & 0.9959 & 0.2164 & 0.9756 \\
\hline \multirow{3}{*}{ PR } & Negative $(n=19)$ & $\begin{array}{c}1.48 \\
(1.13-1.86)\end{array}$ & $\begin{array}{c}13.5 \\
(8.0-22.9)\end{array}$ & $\begin{array}{c}27.1 \\
(21.9-29.1)\end{array}$ & $\begin{array}{c}96.8 \\
(84.0-173.4)\end{array}$ & $\begin{array}{c}8.6 \\
(7.2-10.2)\end{array}$ \\
\hline & Positive $(n=85)$ & $\begin{array}{c}1.44 \\
(1.20-1.63)\end{array}$ & $\begin{array}{c}14.7 \\
(9.8-22.0)\end{array}$ & $\begin{array}{c}25.6 \\
(21.6-32.1)\end{array}$ & $\begin{array}{c}94.0 \\
(73.1-122.6)\end{array}$ & $\begin{array}{c}7.7 \\
(6.6-9.3)\end{array}$ \\
\hline & $p$-values ${ }^{\mathrm{b}}$ & 0.7144 & 0.6346 & 0.9062 & 0.2778 & 0.1288 \\
\hline \multirow{3}{*}{ HER2 } & Negative $(n=76)$ & $\begin{array}{c}1.45 \\
(1.19-1.70)\end{array}$ & $\begin{array}{c}14.3 \\
(9.1-21.9)\end{array}$ & $\begin{array}{c}26.0 \\
(21.7-31.6)\end{array}$ & $\begin{array}{c}94.7 \\
(73.0-125.7)\end{array}$ & $\begin{array}{c}7.7 \\
(6.5-9.2)\end{array}$ \\
\hline & Positive/Equivocal $(n=28)$ & $\begin{array}{c}1.46 \\
(1.14-1.73)\end{array}$ & $\begin{array}{c}16.3 \\
(10.2-24.6)\end{array}$ & $\begin{array}{c}26.2 \\
(20.8-31.2)\end{array}$ & $\begin{array}{c}96.4 \\
(75.3-135.4)\end{array}$ & $\begin{array}{c}8.4 \\
(7.2-10.2)\end{array}$ \\
\hline & $p$-values ${ }^{c}$ & 0.9357 & 0.5001 & 0.6788 & 0.8032 & 0.0946 \\
\hline \multirow{3}{*}{$\mathrm{TN}$} & No $(n=95)$ & $\begin{array}{c}1.45 \\
(1.17-1.69)\end{array}$ & $\begin{array}{c}15.0 \\
(9.8-22.5)\end{array}$ & $\begin{array}{c}26.0 \\
(21.6-31.7)\end{array}$ & $\begin{array}{c}94.3 \\
(73.1-124.4)\end{array}$ & $\begin{array}{c}7.9 \\
(6.6-9.4)\end{array}$ \\
\hline & Yes $(n=6)$ & $\begin{array}{c}1.30 \\
(1.18-1.71)\end{array}$ & $\begin{array}{c}8.5 \\
(7.2-11.3)\end{array}$ & $\begin{array}{c}25.7 \\
(21.9-29.1)\end{array}$ & $\begin{array}{c}152.2 \\
(113.4-177.7)\end{array}$ & $\begin{array}{c}7.5 \\
(6.5-8.3)\end{array}$ \\
\hline & $p$-values ${ }^{b}$ & 0.6011 & 0.0266 & 0.775 & 0.0384 & 0.4641 \\
\hline \multirow{3}{*}{ LN metastasis } & No $(n=88)$ & $\begin{array}{c}1.45 \\
(1.19-1.68)\end{array}$ & $\begin{array}{c}15.0 \\
(9.3-22.6)\end{array}$ & $\begin{array}{c}25.8 \\
(21.7-31.5)\end{array}$ & $\begin{array}{c}94.3 \\
(73.3-126.0)\end{array}$ & $\begin{array}{c}7.8 \\
(6.7-9.3)\end{array}$ \\
\hline & Yes $(n=16)$ & $\begin{array}{c}1.38 \\
(1.14-1.93)\end{array}$ & $\begin{array}{c}13.4 \\
(9.7-20.3)\end{array}$ & $\begin{array}{c}26.6 \\
(20.5-31.7)\end{array}$ & $\begin{array}{c}108.3 \\
(80.7-134.5)\end{array}$ & $\begin{array}{c}8.8 \\
(6.5-10.3)\end{array}$ \\
\hline & $p$-values ${ }^{b}$ & 0.8429 & 0.6654 & 0.9139 & 0.3605 & 0.502 \\
\hline \multirow{4}{*}{ Stage } & Stage $0 \sim 1 /$ LCIS $(n=77)$ & $\begin{array}{c}1.44 \\
(1.18-1.67)\end{array}$ & $\begin{array}{c}14.7 \\
(9.0-22.3)\end{array}$ & $\begin{array}{c}25.6 \\
(21.6-31.3)\end{array}$ & $\begin{array}{c}94.6 \\
(73.4-127.6)\end{array}$ & $\begin{array}{c}7.8 \\
(6.6-9.2)\end{array}$ \\
\hline & Stage $2(n=19)$ & $\begin{array}{c}1.48 \\
(1.28-1.86)\end{array}$ & $\begin{array}{c}16.0 \\
(9.3-22.8)\end{array}$ & $\begin{array}{c}25.1 \\
(21.6-30.2)\end{array}$ & $\begin{array}{c}103.3 \\
(82.5-131.0)\end{array}$ & $\begin{array}{c}8.7 \\
(6.8-10.2)\end{array}$ \\
\hline & Stage $3(n=8)$ & $\begin{array}{c}1.19 \\
(1.04-1.89)\end{array}$ & $\begin{array}{c}14.0 \\
(11.3-18.5)\end{array}$ & $\begin{array}{c}31.7 \\
(22.9-35.8)\end{array}$ & $\begin{array}{c}94.3 \\
(75.0-110.5)\end{array}$ & $\begin{array}{c}7.9 \\
(6.5-9.6)\end{array}$ \\
\hline & $p$-values ${ }^{\mathrm{c}}$ & 0.5472 & 0.8976 & 0.447 & 0.6803 & 0.5515 \\
\hline
\end{tabular}

Abbreviations: ER, estrogen receptor; PR, progesterone receptor; HER2, human epidermal growth factor receptor 2; TN, triple-negative; LN, lymph node; LCIS, lobular carcinoma in situ. a Results are presented as medians (interquartile ranges). ${ }^{\mathrm{b}} p$-values estimated through Wilcoxon rank sum test and ${ }^{\mathrm{c}}$ Kruskal-Wallis test.

\subsection{Correlations among Vitamin Markers and Biochemical Factors}

The correlations among serum concentrations of vitamins and biochemical parameters were analyzed (Table 5). Vitamin E concentration showed a weak positive correlation with LDL $(r=0.42$, $p<0.0001)$ and a moderate positive correlation with total cholesterol $(r=0.586, p<0.0001)$. 
Table 5. Correlations among vitamin status, basal characteristics, and biochemical parameters of the study population ${ }^{\mathrm{a}}$.

\begin{tabular}{|c|c|c|c|c|c|c|c|c|c|c|}
\hline & Age & BMI & TP & Albumin & AST & ALT & ALP & HDL & LDL & TC \\
\hline Vitamin A & $0.298^{c}$ & 0.093 & -0.110 & -0.023 & $0.257^{\mathrm{c}}$ & $0.261^{c}$ & $0.182^{c}$ & -0.026 & 0.096 & $0.183^{c}$ \\
\hline Vitamin D & $0.156^{\mathrm{b}}$ & -0.08 & -0.032 & 0.059 & $0.196^{c}$ & $0.177^{c}$ & 0.026 & 0.096 & -0.015 & 0.015 \\
\hline Vitamin E & $0.292^{c}$ & 0.101 & 0.062 & -0.027 & $0.153^{b}$ & $0.186^{c}$ & 0.067 & 0.119 & $0.421^{c}$ & $0.586^{c}$ \\
\hline Methylmalonic acid & $0.164^{\mathrm{b}}$ & -0.029 & -0.122 & -0.067 & 0.042 & -0.027 & 0.119 & 0.026 & 0.027 & 0.064 \\
\hline Homocysteine & $0.206^{c}$ & $0.137^{b}$ & 0.009 & -0.105 & 0.052 & 0.005 & $0.207^{c}$ & $-0.159^{b}$ & 0.089 & 0.093 \\
\hline
\end{tabular}

Abbreviations: BMI, body mass index; TP, total protein; AST, aspartate aminotransferase; ALT, alanine aminotransferase; ALP, alkaline phosphatase; HDL, high density lipoprotein; LDL, low density lipoprotein; TC, total cholesterol. ${ }^{a}$ Results are described as Spearman's correlation coefficients. ${ }^{\mathrm{b}} p$-values $<0.05 .{ }^{\mathrm{c}} p$-values $<0.01$.

\section{Discussion}

In this study, we measured serum levels of vitamins in female Korean patients with breast cancer or benign breast disease, and in healthy controls. We also analyzed possible relationships between serum levels of vitamins and molecular subtypes of breast cancer, the presence of lymph node metastasis, and tumor stages. The present study is one of only a few studies to investigate serum levels of multiple vitamins and to examine the association between serum levels of vitamins and breast cancer in an Asian population.

As previously reported, our study results showed that patients with breast cancer were considered to be more frequently obese than healthy controls or patients with benign breast disease. Obesity increases the risk of postmenopausal breast cancer, since adipose tissue enhances the mammary estrogen signaling pathway. In addition, several studies found that adipose tissue sequesters vitamin $\mathrm{D}$ and leads to relatively low serum vitamin D levels in obese people. However, the consistency of the role of vitamin D as a mediator on the link between obesity and cancer is still low [23]. The relationship between obesity, vitamin $\mathrm{D}$, and cancer risk needs to be further studied.

Numerous studies have proposed that vitamins have protective effects against breast carcinogenesis, but results have been inconsistent. Results of previous research into the roles of vitamins in breast cancer are summarized in Table 6. 
Table 6. A summary of previous studies of vitamin status in patients with breast cancer.

\begin{tabular}{|c|c|c|c|c|c|}
\hline Studied Vitamins & Region & $\begin{array}{c}\text { Numbers } \\
\text { (Cases/Controls) }\end{array}$ & Analytes & Results & References \\
\hline Vitamin A & Italy & 208 & Retinol $(\mu \mathrm{mol} / \mathrm{L})$ & $\begin{array}{c}\text { BC patients ( } \geq 55 \text { year-old) with low retinol levels had a poorer prognosis } \\
\text { (hazard ratio }=3.58,95 \% \mathrm{CI}=1.50-8.57) .\end{array}$ & Formelli, 2009 [24] \\
\hline Vitamin E & India & $75 / 75 / 50^{\mathrm{a}}$ & $\alpha$-tocopherol (ug/mL) & $\begin{array}{l}\text { BC and BBD patients had significantly lower vitamin E levels }(p<0.001), \\
\text { and decreased vitamin E was directly related to higher stage BC. }\end{array}$ & Chitkara, 1996 [25] \\
\hline Vitamin A and $\mathrm{E}$ & USA & $105 / 203$ & $\begin{array}{c}\text { Retinol }(\mu \mathrm{mol} / \mathrm{L}) \\
\alpha \text {-tocopherol }(\mu \mathrm{mol} / \mathrm{L})\end{array}$ & No evidence for protective effects of $\alpha$-tocopherol or retinol in BC. & Dorgan, 1998 [26] \\
\hline Vitamin $\mathrm{A}$ and $\mathrm{E}$ & Sweden & $201 / 290$ & $\begin{array}{c}\text { Retinol }(\mu \mathrm{mol} / \mathrm{L}) \\
\alpha \text {-tocopherol }(\mu \mathrm{mol} / \mathrm{L})\end{array}$ & $\begin{array}{l}\text { No significant associations between plasma levels of } \alpha \text {-tocopherol or retinol } \\
\text { and BC risk. }\end{array}$ & Hultén, 2001 [27] \\
\hline Vitamin $\mathrm{A}$ and $\mathrm{E}$ & Korea & $160 / 229$ & $\begin{array}{c}\text { Retinol }(\mu \mathrm{g} / \mathrm{dL}) \\
\alpha \text {-tocopherol }(\mu \mathrm{g} / \mathrm{mL})\end{array}$ & $\begin{array}{c}\text { Significantly lower } \alpha \text {-tocopherol and retinol levels in BC patients than in } \\
\text { controls }(p<0.001) \text {. Significantly decreased BC risks with increasing } \\
\alpha \text {-tocopherol and retinol levels }(\alpha \text {-tocopherol, OR }=0.13,95 \% \mathrm{CI}=0.03-0.66 \text {; } \\
\text { Retinol, OR }=0.08,95 \% \mathrm{CI}=0.01-0.45)\end{array}$ & Kim, 2001 [28] \\
\hline Vitamin $\mathrm{A}$ and $\mathrm{E}$ & Australia & $153 / 151$ & $\begin{array}{l}\text { Retinol }(\mu \mathrm{mol} / \mathrm{L}) \\
\alpha \text {-tocopherol }(\mu \mathrm{mol} / \mathrm{L})\end{array}$ & $\begin{array}{c}\text { Significant reduction of BC risk with increasing retinol levels }(\mathrm{OR}=0.53,95 \% \\
\text { CI } 0.28-1.01, p=0.04), \text { but no significant association with BC risk and } \\
\alpha \text {-tocopherol levels (OR }=1.27,95 \% \mathrm{CI}=0.69-2.35, \mathrm{~N} \text {.S.) }\end{array}$ & Ching, 2002 [29] \\
\hline Vitamin $\mathrm{A}$ and $\mathrm{E}$ & USA & $969 / 969$ & $\begin{array}{c}\text { Retinol }(\mu \mathrm{mol} / \mathrm{L}) \\
\alpha \text {-tocopherol }(\mu \mathrm{mol} / \mathrm{L})\end{array}$ & $\begin{array}{l}\text { Retinol }(p=0.03) \text { and } \alpha \text {-tocopherol }(p=0.01) \text { levels were associated with a } \\
\text { significantly decreased risk of BC with LN metastasis. }\end{array}$ & Tamimi, 2005 [30] \\
\hline Vitamin A and $\mathrm{E}$ & France & $366 / 720$ & $\begin{array}{c}\text { Retinol }(\mu \mathrm{mol} / \mathrm{L}), \\
\alpha \text {-tocopherol }(\mu \mathrm{mol} / \mathrm{L})\end{array}$ & $\begin{array}{l}\text { No significant associations between } \mathrm{BC} \text { risk and serum carotenoids (OR }=0.74 \text {, } \\
95 \% \mathrm{CI}=0.47-1.16, \mathrm{~N} . \mathrm{S} \text {.), } \alpha \text {-tocopherols }(\mathrm{OR}=0.70,95 \% \mathrm{CI}=0.44-1.13, \mathrm{~N} . \mathrm{S} \text {.), } \\
\text { or retinol }(\mathrm{OR}=0.85,95 \% \mathrm{CI}=0.53-1.35, \mathrm{~N} . \mathrm{S} \text {.) in postmenopausal women. }\end{array}$ & Maillard, 2010 [31] \\
\hline Vitamin A and E & Korea & $376 / 304$ & $\begin{array}{c}\text { Retinol }(\mu \mathrm{g} / \mathrm{dL}) \\
\alpha \text {-tocopherol }(\mu \mathrm{g} / \mathrm{dL})\end{array}$ & $\begin{array}{l}\text { Higher retinol level was associated with lower } \mathrm{BC} \text { risk }(\mathrm{OR}=0.13,95 \% \\
\qquad \mathrm{CI}=0.07-0.26) \text {, but this was not true for } \alpha \text {-tocopherol level. }\end{array}$ & Kim, 2010 [32] \\
\hline Vitamin D & USA & $701 / 724$ & $\begin{array}{l}25(\mathrm{OH}) \mathrm{D}(\mathrm{ng} / \mathrm{mL}) \\
1,25(\mathrm{OH})_{2} \mathrm{D}(\mathrm{ng} / \mathrm{mL})\end{array}$ & $\begin{array}{l}\text { High levels of vitamin } \mathrm{D} \text { were associated with lower } \mathrm{BC} \text { risk, but this was not } \\
\text { statistically significant }(25(\mathrm{OH}) \mathrm{D}, \mathrm{RR}=0.73,95 \% \mathrm{CI}=0.49-1.07 \text {, N.S.; } \\
\qquad 1,25(\mathrm{OH})_{2} \mathrm{D}, \mathrm{RR}=0.76,95 \% \mathrm{CI}=0.52-1.11 \text {, N.S.). }\end{array}$ & Bertone-Johnson, 2005 [33] \\
\hline Vitamin D & USA & $1005 / 1005$ & $\begin{array}{c}25(\mathrm{OH}) \mathrm{D}(\mathrm{ng} / \mathrm{mL}) \\
1,25(\mathrm{OH})_{2} \mathrm{D}(\mathrm{pg} / \mathrm{mL})\end{array}$ & $\begin{array}{l}\text { No inverse association between vitamin D levels and BC risk }(25(\mathrm{OH}) \mathrm{D}, \\
\mathrm{RR}=1.04,95 \% \mathrm{CI}=0.75-1.45, \mathrm{~N} . \mathrm{S} . ; 1,25(\mathrm{OH})_{2} \mathrm{D}, \mathrm{RR}=1.23,95 \% \\
\mathrm{CI}=0.91-1.68, \mathrm{~N} \text {.S.). }\end{array}$ & Freedman, 2008 [35] \\
\hline Vitamin D & USA & $1026 / 1075$ & 25(OH)D (ng/mL) & $\begin{array}{l}\text { Mean vitamin } \mathrm{D} \text { levels were significantly lower in } \mathrm{BC} \text { patients than in controls } \\
(p<0.0001) \text {. There was an inverse association between vitamin } \mathrm{D} \text { and } \mathrm{BC} \text { risk } \\
\text { in a concentration-dependent manner }(p=0.002) .\end{array}$ & Crew, 2009 [36] \\
\hline
\end{tabular}


Table 6. Cont.

\begin{tabular}{|c|c|c|c|c|c|}
\hline Studied Vitamins & Region & $\begin{array}{c}\text { Numbers } \\
\text { (Cases/Controls) }\end{array}$ & Analytes & Results & References \\
\hline Vitamin D & Germany & $1394 / 1365$ & $25(\mathrm{OH}) \mathrm{D}(\mathrm{nM})$ & $\begin{array}{l}\text { Significant inverse association between vitamin D levels and post-menopausal } \\
\text { BC risk }(\mathrm{OR}=0.31,95 \% \mathrm{CI}=0.24-0.42, p<0.0001)\end{array}$ & Abbas, 2008 [34] \\
\hline Vitamin D & Sweden & $764 / 764$ & $\begin{array}{l}25(\mathrm{OH}) \mathrm{D}_{2}(\mathrm{nmol} / \mathrm{L}) \\
25(\mathrm{OH}) \mathrm{D}_{3}(\mathrm{nmol} / \mathrm{L})\end{array}$ & $\begin{array}{l}\text { Weak inverse association between } 25(\mathrm{OH}) \mathrm{D}_{3} \text { levels and } \mathrm{BC} \text { risk, but this was } \\
\text { not statistically significant. There was a weaker association between total } \\
\qquad 25(\mathrm{OH}) \mathrm{D}\left(25(\mathrm{OH}) \mathrm{D}_{2}+\mathrm{D}_{3}\right) \text { and } \mathrm{BC} \text {. }\end{array}$ & Almquist, 2010 [37] \\
\hline Vitamin D & USA & $579 / 574$ & 25(OH)D (ng/mL) & $\begin{array}{l}\text { Significantly lower vitamin D levels in BC patients }(p<0.001) \text {, and lower } \\
\text { vitamin D levels in high grade BC, including ER(-) tumors }(p \leq 0.03) \text { and } \\
\text { TNBC }(p=0.002) .\end{array}$ & Yao, 2011 [38] \\
\hline Vitamin D & Korea & $310^{b}$ & 25(OH)D (ng/mL) & $\begin{array}{c}\text { Vitamin D deficient individuals }(<20 \mathrm{ng} / \mathrm{mL}) \text { had increased risk of recurrence } \\
\text { compared with those with sufficient vitamin D levels }(30-150 \mathrm{ng} / \mathrm{mL}) \\
(p=0.002) \text {. Inverse association between vitamin D levels and prognosis of BC } \\
\text { in luminal A ( } p=0.012 \text { ) and luminal B subtypes ( } p=0.023 \text { ), but no association } \\
\text { with prognosis of BC in HER2 }(+) \text { or TN subtypes. }\end{array}$ & Kim, 2011 [39] \\
\hline Vitamin D & Germany & $1295^{b}$ & 25(OH)D (nmol/L) & $\begin{array}{c}\mathrm{BC} \text { patients with lower vitamin D levels had a higher risk of death (hazard } \\
\text { ratio }=1.08,95 \% \mathrm{CI}=1.00-1.17 \text { ) and significantly higher risk of distant } \\
\text { recurrence (hazard ratio }=1.14,95 \% \mathrm{CI}=1.05-1.24 \text { ) }\end{array}$ & Vrieling, 2011 [40] \\
\hline Vitamin D & Pakistan & $90 / 90$ & $25(\mathrm{OH})_{2} \mathrm{D}(\mathrm{ng} / \mathrm{mL})$ & $\begin{array}{c}\text { Significantly lower vitamin D levels in BC patients than in controls }(p<0.001) \text {. } \\
\text { However, no significant association between tumor characteristics and } \\
\text { vitamin D levels among BC patients. }\end{array}$ & Imtiza, 2012 [41] \\
\hline Vitamin D & USA & $194 / 194$ & 25(OH)D (ng/mL) & $\begin{array}{c}\text { Significantly lower vitamin D levels in BC patients than in controls }(p=0.02) \text {. } \\
\text { Patients with suboptimal vitamin D levels }(<32 \mathrm{ng} / \mathrm{mL}) \text { had significantly } \\
\text { higher risk of having ER(-) }(\mathrm{OR}=2.59,95 \% \mathrm{CI}=1.08-6.23) \text { and TN }(\mathrm{OR}=3.15 \text {, } \\
95 \% \mathrm{CI}=1.05-9.49) \mathrm{BC} \text { than those with optimal vitamin D levels }(\geq 32 \mathrm{ng} / \mathrm{mL}) \text {. } \\
\text { BC patients with a basal-like subtype had lower vitamin D levels than BC } \\
\text { patients with a luminal subtype }(p=0.04) .\end{array}$ & Peppone, 2012 [42] \\
\hline Vitamin D & Korea & $3634 / 17,133$ & 25(OH)D (ng/mL) & $\begin{array}{c}\text { Significantly higher } B C \text { risk in women with vitamin } D \text { deficiency than those } \\
\text { with sufficient vitamin } D(O R=1.27,95 \% \mathrm{CI}=1.15-1.39) \text {. Significant inverse } \\
\text { association between vitamin D levels and } \mathrm{HR}(-) \mathrm{BC} \text {, particularly TNBC } \\
(\mathrm{OR}=1.45,95 \% \mathrm{CI} 1.15-1.82) .\end{array}$ & Park, 2015 [43] \\
\hline Vitamin D & Sweden & $764 / 764$ & $25(\mathrm{OH}) \mathrm{D}_{3}(\mathrm{nmol} / \mathrm{L})$ & $\begin{array}{l}\text { Women with vitamin D levels of } \geq 77 \text { but } \leq 97 \mathrm{nmol} / \mathrm{L} \text { had a significantly lower } \\
\text { risk of an ER(-) tumor }(\mathrm{OR}=0.46,95 \% \mathrm{CI}=0.23-0.94), \mathrm{PR}(-)(\mathrm{OR}=0.66,95 \% \\
\mathrm{CI}=0.46-0.96) \text { and higher Ki67 tumor expression }(\mathrm{OR}=0.57,95 \% \\
\mathrm{CI}=0.36-0.90) \text { than those with vitamin D levels of } \leq 76 \mathrm{nmol} / \mathrm{L} \text {. }\end{array}$ & Shirazi, 2016 [44] \\
\hline
\end{tabular}


Table 6. Cont

\begin{tabular}{|c|c|c|c|c|c|}
\hline Studied Vitamins & Region & $\begin{array}{c}\text { Numbers } \\
\text { (Cases/Controls) }\end{array}$ & Analytes & Results & References \\
\hline Vitamin D & Brazil & $192^{b}$ & 25(OH)D (ng/mL) & $\begin{array}{l}\text { Patients insufficient }(20-29 \mathrm{ng} / \mathrm{mL}) \text { or deficient }(<20 \mathrm{ng} / \mathrm{mL}) \text { for vitamin } \mathrm{D} \text { had } \\
\text { higher proportions of high-grade } \mathrm{BC} \text {, advanced } \mathrm{BC} \text {, metastatic disease, } \\
\text { number of positive LNs, and high Ki- } 67 \text { expression in their tumors }(p<0.05) \text {. }\end{array}$ & $\begin{array}{c}\text { de Sousa Almeida-Filho, } 2017 \\
\text { [45] }\end{array}$ \\
\hline Vitamin B12 & USA & $195 / 195$ & $\begin{array}{c}\text { Folate }(\mathrm{ng} / \mathrm{mL}) \\
\text { Vitamin } \mathrm{B} 12(\mathrm{pg} / \mathrm{mL}) \\
\text { Homocysteine }(\mathrm{nmol} / \mathrm{mL})\end{array}$ & $\begin{array}{c}\text { Significantly lower vitamin B12 levels in BC in postmenopausal women } \\
(p=0.03) \text {. Women with lower vitamin B12 levels showed increased BC risk } \\
(\mathrm{OR}=4.00,95 \% \mathrm{CI}=1.05-15.20) \text {. No association between folate and } \\
\text { homocysteine and BC risk. }\end{array}$ & $\mathrm{Wu}, 1999$ [46] \\
\hline Vitamin B12 & USA & $712 / 712$ & $\begin{array}{c}\text { Folate }(\mathrm{ng} / \mathrm{mL}) \\
\text { Vitamin } \mathrm{B} 12(\mathrm{pg} / \mathrm{mL}) \\
\text { Homocysteine }(\mathrm{nmol} / \mathrm{mL})\end{array}$ & $\begin{array}{c}\text { Significantly lower folate concentrations in BC than in controls }(p=0.009) \text {. } \\
\text { Inverse association between vitamin B12 levels and risk of BC only among } \\
\text { premenopausal women ( } R R=0.36,95 \% \mathrm{CI}=0.15-0.86) \text {. No association } \\
\text { between homocysteine and BC risk. }\end{array}$ & Zhang, 2003 [47] \\
\hline Vitamin B12 & USA & $848 / 848$ & $\begin{array}{c}\text { Folate }(\mathrm{ng} / \mathrm{mL}), \\
\text { Vitamin } \mathrm{B} 12(\mathrm{pg} / \mathrm{mL})\end{array}$ & $\begin{array}{c}\text { No significant association between folate and vitamin B12 levels and overall } \\
\text { risk of BC. Higher folate levels were associated with an increased risk of } \\
\text { premenopausal BC }(p=0.04) .\end{array}$ & Lin, 2008 [48] \\
\hline Vitamin B12 & USA & $812 / 812$ & $\begin{array}{c}\text { Cysteine }(\mathrm{nmol} / \mathrm{mL}) \\
\text { Homocysteine }(\mathrm{nmol} / \mathrm{mL})\end{array}$ & $\begin{array}{c}\text { Positive association between cysteine levels and } \mathrm{BC} \text { risk }(\mathrm{RR}=1.65,95 \% \\
\mathrm{CI}=1.04-2.61, p=0.04) \text {. Patients who had low folate levels tend to have } \\
\text { positive correlations between concentrations of homocysteine and cysteine } \\
\text { and risk of } \mathrm{BC} \text { development }(p=0.04 \text { and } 0.002) . \text { No association between } \\
\text { homocysteine and overall BC risk. }\end{array}$ & Lin, 2010 [49] \\
\hline Vitamin B12 & Canada & $164^{\mathrm{b}}$ & $\begin{array}{c}\text { Folate }(\mathrm{ng} / \mathrm{mL}) \\
\text { Vitamin } \mathrm{B} 12(\mathrm{pmol} / \mathrm{L})\end{array}$ & $\begin{array}{l}\text { Significant association between high plasma folate levels }(>24.4 \mathrm{ng} / \mathrm{mL}) \text { and } \\
\text { increased BC risk }(\mathrm{HR}=3.20,95 \% \mathrm{CI}=1.03-9.92, p=0.04) \text { than low folate } \\
(\leq 24.4 \mathrm{ng} / \mathrm{mL}) \text {. No significant association between vitamin B12 concentration } \\
\text { and BC risk. }\end{array}$ & Kim, 2016 [50] \\
\hline Vitamin B12 & USA & 610/1207 & $\begin{array}{c}\text { Folate }(\mathrm{ng} / \mathrm{mL}) \\
\text { Vitamin } B 12(\mathrm{pg} / \mathrm{mL}) \\
\text { Homocysteine }(\mathrm{nmol} / \mathrm{mL})\end{array}$ & $\begin{array}{c}\text { Plasma vitamin B12 was positively associated with higher risk of overall BC } \\
(95 \% \mathrm{CI}=1.17-2.29, p=0.02), \text { and plasma folate was positively associated } \\
\text { with risk of invasive BC. }\end{array}$ & Houghton, 2019 [51] \\
\hline
\end{tabular}


In the present study, serum vitamin A and E concentrations were significantly lower in patients with breast cancer and in patients with benign breast disease than in healthy controls. Similarly, another report published in Korea reported significantly lower serum levels of carotenoid and $\alpha$-tocopherol in women with breast cancer than in healthy subjects $[27,28]$. In addition, we found significantly lower concentrations of total cholesterol in breast cancer patients as well as benign breast disease patients than healthy controls. According to a study by Llaverias et al., plasma cholesterol levels were decreased during tumor development but not in advance to tumor initiation, indicating an increased utilization of cholesterol by tumor cells [52]. Vitamins A and E are fat-soluble vitamins that have both been reported to have significant correlations with serum cholesterol level $[53,54]$. Tumor demand for cholesterol may have resulted in low serum levels of total cholesterol, and therefore low levels of vitamin $\mathrm{A}$ and $\mathrm{E}$ in both benign breast disease patients and breast cancer patients in our study.

We found that the serum concentration of vitamin A was associated with a seven-fold decrease in risk of benign breast disease and a six-fold decrease in risk of breast cancer, consistent with previous findings that high levels of vitamin A were significantly associated with reduced risk of breast cancer $[29,32]$. Several studies have shown that a metabolite of vitamin A (all-trans retinoic acid, atRA) induces re-differentiation of transformed cells during the early stages of the neoplastic process and promotes the apoptosis of human breast cancer cells by regulating the Tet Methylcytosine Dioxygenase 2-Protein Kinase C zeta (TET2-PKC $\zeta$ ) pathway [55-57]. These results demonstrate that a low concentration of vitamin A may promote the proliferation of tumor cells in breast carcinogenesis, consistent with previous findings that breast cancer patients with a low vitamin A level tended to have advanced stage disease and a poorer prognosis than those with a high vitamin A level $[24,58]$.

Vitamin D is the most widely investigated vitamin in terms of breast cancer [33-45,59]. The importance of vitamin $\mathrm{D}$ in breast cancer patients has been emphasized because calcitriol, the active metabolite of vitamin $\mathrm{D}$, is known to have antiproliferative effects by activating apoptotic pathways and inhibiting angiogenesis [60]. Our data showed that serum vitamin D concentrations had no statistically significant differences among patients with breast cancer, patients with breast benign disease, and healthy controls. However, severe vitamin D deficiencies were more frequently found in patients with breast cancer than in healthy controls, consistent with previous studies [36,39,41-43]. Women with insufficient vitamin D levels have a higher risk of breast cancer and poorer overall survival than those with sufficient levels of vitamin D [33,34,36,40,59].

Low levels of vitamin B12 lead to chromosome breakage and disrupt DNA repair by influencing DNA methylation [9], although its role remains poorly understood as the published data are scarce and inconsistent [46-51]. A reduced vitamin B12 level can decrease the activity of S-adenosylmethionine (SAM) for DNA methylation and regulate gene expression, inducing breast carcinogenesis as a result [9]. We used serum methylmalonic acid and homocysteine as biomarkers of vitamin B12. Methylmalonic acid and homocysteine are likely to be more sensitive biomarkers of early vitamin B12 deficiency than direct vitamin B12 assay [61]. We observed vitamin B12 deficiency (defined as increased levels of methylmalonic acid or homocysteine) only in a couple of patients with breast cancer and patients with benign breast disease, which was statistically not significant. A study proposed by Sellers et al. revealed that women with low folate intake were at higher risk of ER-negative breast cancers because methyl deficiency induces the promotor region of the ER gene to be regionally hypermethylated, resulting in reduced protein expression [62]. Similarly, in our study, patients with triple-negative breast cancer had significantly higher methylmalonic acid levels than those with other breast cancer subtypes. However, serum concentration of methylmalonic acid is known to be influenced by multiple factors including vitamin B12 deficiency, aging, diet, or genetic mutations [63]. Further detailed studies are needed to understand the relationship between vitamin B12 and breast cancer.

In recent years, the classification of breast cancer based on histologic characteristics and gene expression has led to an improved understanding of disease pathogenesis and prognosis [42]. Triple-negative breast cancer in particular has a poor prognosis due to its aggressive behavior and lack of effective targeted therapies [18]. There have been efforts to identify risk factors for these 
cancers. Our findings that serum vitamin D levels were significantly lower in ER-negative and triple-negative breast cancer patients than patients with other breast cancer subtypes are in agreement with previous research [38,42-45,59]. Calcitriol affects the proliferation of breast cancer cells by regulating the expression of $\mathrm{ER} \alpha[64,65]$. This may explain the association between low vitamin $\mathrm{D}$ levels and aggressive breast cancers.

In our study, the concentration of vitamin E showed the strongest correlation with the concentration of total cholesterol when analyzing correlations between serum concentrations of vitamins and parameters associated with nutritional status. Vitamin $\mathrm{E}$ has been shown to have significant correlations with serum cholesterol, especially concentrations of lipoprotein carriers [54,66].

A strength of our study is that we measured serum levels of various vitamins in Korean breast cancer patients. Furthermore, we evaluated serum levels of these vitamins in patients with benign breast disease. We assessed the relevance of serum vitamin concentrations in accordance with molecular subtypes of breast cancer, lymph node metastasis, and tumor stages, which has only been explored previously for vitamin D. We found that concentrations of vitamins differed according to breast cancer subtypes, indicating that vitamins may have a more significant effect in breast cancers with specific characteristics. Our study suggests foundational results to support future investigations for further evidence of the roles of vitamins in breast cancer etiology. Further research evaluating relationships among serum vitamins levels, usage of dietary supplements, and treatment outcomes is needed to identify the optimal therapeutic strategies for breast cancer patients.

Our study also had several limitations. Although we evaluated several biochemical markers, information about dietary patterns (including nutrient supplements or alcohol intake) was not fully considered. Information about vitamin supplement consumption was collected via medical records, but missing data existed in some patients; thus, comprehensive interpretation may not have been provided. Vitamin supplements were taken mostly by patients with benign breast disease and patients with breast cancer. Most of the healthy controls did not take supplements (only three of them took supplements). However, each three groups of the study population showed no significant differences $(p>0.05)$ of serum vitamin concentrations between patients who took supplements and those who did not. Therefore, intake of vitamin supplements would not have affected our results. Measuring serum vitamin concentrations at a single time point may also not represent long-term vitamin condition. Future well-designed studies with large patient cohorts are needed to further explore the importance of vitamins in breast cancer.

\section{Conclusions}

In conclusion, we assessed serum concentrations of multiple vitamins or vitamin biomarkers in Korean breast cancer patients, benign breast disease patients, and healthy controls using established methodologies. Patients with breast cancer as well as patients with benign breast disease had lower concentrations of vitamins $\mathrm{A}$ and $\mathrm{E}$, and higher frequencies of single vitamin deficiencies, including vitamin A and D, than healthy controls. Moreover, tumor subtypes known to develop more aggressively and have poorer outcomes were associated with reduced levels of vitamin $\mathrm{D}$, suggesting potential subtype-specific roles and impacts of vitamins in breast cancer. Our study provides important background information regarding the potential effects of vitamins in breast cancer.

Supplementary Materials: The following are available online at http://www.mdpi.com/2072-6643/12/9/2831/s1. Figure S1: An example of multiple reaction monitoring (MRM) chromatograms of analytes (left) and its internal standards (right) in liquid chromatography with tandem mass spectrometry (LC-MS/MS) analysis. (a) 25-hydroxyvitamin D2 and (b) 25-hydroxyvitamin D3.

Author Contributions: S.-Y.L. designed the study. R.C., H.J.C., J.M.R., S.K.L., J.Y., S.W.K. and J.E.L. were responsible for data acquisition. J.A.K., H.W., S.K. and S.-Y.L. analyzed and interpreted the data. J.A.K., J.E.L. and S.-Y.L. wrote the article. Conceptualization: S.-Y.L.; methodology: J.A.K., R.C., S.-Y.L.; validation: J.A.K., S.-Y.L.; formal analysis: J.A.K., H.W., S.K., S.-Y.L.; funding acquisition: S.-Y.L., J.E.L.; investigation: J.A.K., R.C., H.J.C., J.M.R., S.K.L., J.Y., S.W.K., J.E.L.; data curation: J.A.K., H.W., S.K.; writing-original draft preparation: J.A.K., S.-Y.L.; writing-review and editing: J.E.L., S.-Y.L. All authors have read and agreed to the published version of the manuscript. 
Funding: This research was supported by the Bio \& Medical Technology Development Program of the National Research Foundation (NRF) funded by the Ministry of Science, ICT \& Future Planning (2016M3A9B6026775).

Conflicts of Interest: The authors declare no conflict of interest.

\section{References}

1. Baena Ruiz, R.; Salinas Hernandez, P. Diet and cancer: Risk factors and epidemiological evidence. Maturitas 2014, 77, 202-208. [CrossRef]

2. Chajes, V.; Romieu, I. Nutrition and breast cancer. Maturitas 2014, 77, 7-11. [CrossRef]

3. Young, V.R.; Newberne, P.M. Vitamins and cancer prevention: Issues and dilemmas. Cancer 1981, 47, 1226-1240. [CrossRef]

4. Menkes, M.S.; Comstock, G.W.; Vuilleumier, J.P.; Helsing, K.J.; Rider, A.A.; Brookmeyer, R. Serum beta-carotene, vitamins A and E, selenium, and the risk of lung cancer. N. Engl. J. Med. 1986, 315, 1250-1254. [CrossRef]

5. Ziegler, R.G. Vegetables, fruits, and carotenoids and the risk of cancer. Am. J. Clin. Nutr. 1991, 53, 251s-259s. [CrossRef]

6. Knekt, P.; Jarvinen, R.; Seppanen, R.; Hellovaara, M.; Teppo, L.; Pukkala, E.; Aromaa, A. Dietary flavonoids and the risk of lung cancer and other malignant neoplasms. Am. J. Epidemiol. 1997, 146, 223-230. [CrossRef]

7. Lee, I.M. Antioxidant vitamins in the prevention of cancer. Proc. Assoc. Am. Physicians 1999, 111, 10-15. [CrossRef]

8. Michels, K.B.; Mohllajee, A.P.; Roset-Bahmanyar, E.; Beehler, G.P.; Moysich, K.B. Diet and breast cancer: A review of the prospective observational studies. Cancer 2007, 109, 2712-2749. [CrossRef]

9. Mamede, A.C.; Tavares, S.D.; Abrantes, A.M.; Trindade, J.; Maia, J.M.; Botelho, M.F. The role of vitamins in cancer: A review. Nutr. Cancer 2011, 63, 479-494. [CrossRef]

10. De Cicco, P.; Catani, M.V.; Gasperi, V.; Sibilano, M.; Quaglietta, M.; Savini, I. Nutrition and breast cancer: A literature review on prevention, treatment and recurrence. Nutrients 2019, 11, 1514. [CrossRef]

11. Velie, E.M.; Schairer, C.; Flood, A.; He, J.P.; Khattree, R.; Schatzkin, A. Empirically derived dietary patterns and risk of postmenopausal breast cancer in a large prospective cohort study. Am. J. Clin. Nutr. 2005, 82, 1308-1319. [CrossRef] [PubMed]

12. Aune, D.; Chan, D.S.; Vieira, A.R.; Navarro Rosenblatt, D.A.; Vieira, R.; Greenwood, D.C.; Norat, T. Dietary compared with blood concentrations of carotenoids and breast cancer risk: A systematic review and meta-analysis of prospective studies. Am. J. Clin. Nutr. 2012, 96, 356-373. [CrossRef] [PubMed]

13. Dupont, W.D.; Page, D.L. Breast cancer risk associated with proliferative disease, age at first birth, and a family history of breast cancer. Am. J. Epidemiol. 1987, 125, 769-779. [CrossRef] [PubMed]

14. Dupont, W.D.; Parl, F.F.; Hartmann, W.H.; Brinton, L.A.; Winfield, A.C.; Worrell, J.A.; Schuyler, P.A.; Plummer, W.D. Breast cancer risk associated with proliferative breast disease and atypical hyperplasia. Cancer 1993, 71, 1258-1265. [CrossRef]

15. London, S.J.; Stein, E.A.; Henderson, I.C.; Stampfer, M.J.; Wood, W.C.; Remine, S.; Dmochowski, J.R.; Robert, N.J.; Willett, W.C. Carotenoids, retinol, and vitamin e and risk of proliferative benign breast disease and breast cancer. Cancer Causes Control 1992, 3, 503-512. [CrossRef]

16. Webb, P.M.; Byrne, C.; Schnitt, S.J.; Connolly, J.L.; Jacobs, T.W.; Baer, H.J.; Willett, W.C.; Colditz, G.A. A prospective study of diet and benign breast disease. Cancer Epidemiol. Prev. Biomark. 2004, 13, 1106-1113.

17. Kim, M.K.; Park, Y.G.; Gong, G.; Ahn, S.H. Breast cancer, serum antioxidant vitamins, and p53 protein overexpression. Nutr. Cancer 2002, 43, 159-166. [CrossRef]

18. Pistelli, M.; Pagliacci, A.; Battelli, N.; Santinelli, A.; Biscotti, T.; Ballatore, Z.; Berardi, R.; Cascinu, S. Prognostic factors in early-stage triple-negative breast cancer: Lessons and limits from clinical practice. Anticancer Res. 2013, 33, 2737-2742.

19. World Health Organization. The Asia-Pacific Perspective: Redefining Obesity and Its Treatment; Health Communications Australia: Sydney, Australia, 2000.

20. Oh, J.; Park, H.D.; Kim, S.Y.; Koh, W.J.; Lee, S.Y. Assessment of vitamin status in patients with nontuberculous mycobacterial pulmonary disease: Potential role of vitamin A as a risk factor. Nutrients 2019, 11, 343. [CrossRef] 
21. Binkley, N.; Ramamurthy, R.; Krueger, D. Low vitamin d status: Definition, prevalence, consequences, and correction. Endocrinol. Metab. Clin. N. Am. 2010, 39, 287-301. [CrossRef]

22. Hebel, J.R.; McCarter, R.J. Study Guide to Epidemiology and Biostatistics; Jones \& Bartlett Learning: Burlington, MA, USA, 2011; p. 224.

23. Shanmugalingam, T.; Crawley, D.; Bosco, C.; Melvin, J.; Rohrmann, S.; Chowdhury, S.; Holmberg, L.; Van Hemelrijck, M. Obesity and cancer: The role of vitamin D. BMC Cancer 2014, 14, 712. [CrossRef] [PubMed]

24. Formelli, F.; Meneghini, E.; Cavadini, E.; Camerini, T.; Di Mauro, M.G.; De Palo, G.; Veronesi, U.; Berrino, F.; Micheli, A. Plasma retinol and prognosis of postmenopausal breast cancer patients. Cancer Epidemiol. Prev. Biomark. 2009, 18, 42-48. [CrossRef]

25. Chitkara, N.; Dadoo, R.C.; Bansal, S.; Chugh, K.; Aggarwal, S.K.; Lal, H. Plasma vitamin E levels in carcinoma breast. Indian J. Clin. Biochem. 1996, 11, 162-164. [CrossRef]

26. Dorgan, J.F.; Sowell, A.; Swanson, C.A.; Potischman, N.; Miller, R.; Schussler, N.; Stephenson, H.E., Jr. Relationships of serum carotenoids, retinol, alpha-tocopherol, and selenium with breast cancer risk: Results from a prospective study in Columbia, Missouri (United States). Cancer Causes Control 1998, 9, 89-97. [CrossRef]

27. Hultén, K.; Van Kappel, A.L.; Winkvist, A.; Kaaks, R.; Hallmans, G.; Lenner, P.; Riboli, E. Carotenoids, alpha-tocopherols, and retinol in plasma and breast cancer risk in northern Sweden. Cancer Causes Control 2001, 12, 529-537. [CrossRef]

28. Kim, M.K.; Ahn, S.H.; Lee-Kim, Y.C. Relationship of serum $\alpha$-tocopherol, carotenoids and retinol with the risk of breast cancer. Nutr. Res. 2001, 21,797-809. [CrossRef]

29. Ching, S.; Ingram, D.; Hahnel, R.; Beilby, J.; Rossi, E. Serum levels of micronutrients, antioxidants and total antioxidant status predict risk of breast cancer in a case control study. J. Nutr. 2002, 132, 303-306. [CrossRef]

30. Tamimi, R.M.; Hankinson, S.E.; Campos, H.; Spiegelman, D.; Zhang, S.; Colditz, G.A.; Willett, W.C.; Hunter, D.J. Plasma carotenoids, retinol, and tocopherols and risk of breast cancer. Am. J. Epidemiol. 2005, 161, 153-160. [CrossRef]

31. Maillard, V.; Kuriki, K.; Lefebvre, B.; Boutron-Ruault, M.C.; Lenoir, G.M.; Joulin, V.; Clavel-Chapelon, F.; Chajès, V. Serum carotenoid, tocopherol and retinol concentrations and breast cancer risk in the e3n-epic study. Int. J. Cancer 2010, 127, 1188-1196. [CrossRef]

32. Kim, M.K.; Ahn, S.H.; Son, B.H.; Sung, M.K. Plasma antioxidant concentration, not superoxide dismutase polymorphism, is associated with breast cancer risk in Korean women. Nutr. Res. 2010, 30, 705-713. [CrossRef]

33. Bertone-Johnson, E.R.; Chen, W.Y.; Holick, M.F.; Hollis, B.W.; Colditz, G.A.; Willett, W.C.; Hankinson, S.E. Plasma 25-hydroxyvitamin d and 1,25-dihydroxyvitamin d and risk of breast cancer. Cancer Epidemiol. Prev. Biomark. 2005, 14, 1991-1997. [CrossRef] [PubMed]

34. Abbas, S.; Linseisen, J.; Slanger, T.; Kropp, S.; Mutschelknauss, E.J.; Flesch-Janys, D.; Chang-Claude, J. Serum 25-hydroxyvitamin $\mathrm{d}$ and risk of post-menopausal breast cancer-Results of a large case-control study. Carcinogenesis 2008, 29, 93-99. [CrossRef]

35. Freedman, D.M.; Chang, S.C.; Falk, R.T.; Purdue, M.P.; Huang, W.Y.; McCarty, C.A.; Hollis, B.W.; Graubard, B.I.; Berg, C.D.; Ziegler, R.G. Serum levels of vitamin d metabolites and breast cancer risk in the prostate, lung, colorectal, and ovarian cancer screening trial. Cancer Epidemiol. Prev. Biomark. 2008, 17, 889-894. [CrossRef]

36. Crew, K.D.; Gammon, M.D.; Steck, S.E.; Hershman, D.L.; Cremers, S.; Dworakowski, E.; Shane, E.; Terry, M.B.; Desai, M.; Teitelbaum, S.L.; et al. Association between plasma 25-hydroxyvitamin d and breast cancer risk. Cancer Prev. Res. 2009, 2, 598-604. [CrossRef]

37. Almquist, M.; Bondeson, A.G.; Bondeson, L.; Malm, J.; Manjer, J. Serum levels of vitamin D, pth and calcium and breast cancer risk-A prospective nested case-control study. Int. J. Cancer 2010, 127, 2159-2168. [CrossRef]

38. Yao, S.; Sucheston, L.E.; Millen, A.E.; Johnson, C.S.; Trump, D.L.; Nesline, M.K.; Davis, W.; Hong, C.C.; McCann, S.E.; Hwang, H.; et al. Pretreatment serum concentrations of 25-hydroxyvitamin d and breast cancer prognostic characteristics: A case-control and a case-series study. PLoS ONE 2011, 6, e17251. [CrossRef]

39. Kim, H.J.; Lee, Y.M.; Ko, B.S.; Lee, J.W.; Yu, J.H.; Son, B.H.; Gong, G.Y.; Kim, S.B.; Ahn, S.H. Vitamin d deficiency is correlated with poor outcomes in patients with luminal-type breast cancer. Ann. Surg. Oncol. 2011, 18, 1830-1836. [CrossRef] 
40. Vrieling, A.; Hein, R.; Abbas, S.; Schneeweiss, A.; Flesch-Janys, D.; Chang-Claude, J. Serum 25-hydroxyvitamin $\mathrm{d}$ and postmenopausal breast cancer survival: A prospective patient cohort study. Breast Cancer Res. 2011, 13, R74. [CrossRef]

41. Imtiaz, S.; Siddiqui, N.; Raza, S.A.; Loya, A.; Muhammad, A. Vitamin D deficiency in newly diagnosed breast cancer patients. Indian J. Endocrinol. Metab. 2012, 16, 409-413. [CrossRef]

42. Peppone, L.J.; Rickles, A.S.; Janelsins, M.C.; Insalaco, M.R.; Skinner, K.A. The association between breast cancer prognostic indicators and serum 25-oh vitamin D levels. Ann. Surg. Oncol. 2012, 19, 2590-2599. [CrossRef]

43. Park, S.; Lee, D.H.; Jeon, J.Y.; Ryu, J.; Kim, S.; Kim, J.Y.; Park, H.S.; Kim, S.I.; Park, B.W. Serum 25-hydroxyvitamin d deficiency and increased risk of breast cancer among Korean women: A case-control study. Breast Cancer Res. Treat. 2015, 152, 147-154. [CrossRef]

44. Shirazi, L.; Almquist, M.; Borgquist, S.; Malm, J.; Manjer, J. Serum vitamin d (25ohd3) levels and the risk of different subtypes of breast cancer: A nested case-control study. Breast 2016, 28, 184-190. [CrossRef] [PubMed]

45. de Sousa Almeida-Filho, B.; De Luca Vespoli, H.; Pessoa, E.C.; Machado, M.; Nahas-Neto, J.; Nahas, E.A.P. Vitamin D deficiency is associated with poor breast cancer prognostic features in postmenopausal women. J. Steroid Biochem. Mol. Biol. 2017, 174, 284-289. [CrossRef]

46. Wu, K.; Helzlsouer, K.J.; Comstock, G.W.; Hoffman, S.C.; Nadeau, M.R.; Selhub, J. A prospective study on folate, b12, and pyridoxal 5'-phosphate (b6) and breast cancer. Cancer Epidemiol. Prev. Biomark. 1999, 8, 209-217.

47. Zhang, S.M.; Willett, W.C.; Selhub, J.; Hunter, D.J.; Giovannucci, E.L.; Holmes, M.D.; Colditz, G.A.; Hankinson, S.E. Plasma folate, vitamin b6, vitamin b12, homocysteine, and risk of breast cancer. J. Natl. Cancer Inst. 2003, 95, 373-380. [CrossRef]

48. Lin, J.; Lee, I.M.; Cook, N.R.; Selhub, J.; Manson, J.E.; Buring, J.E.; Zhang, S.M. Plasma folate, vitamin b-6, vitamin b-12, and risk of breast cancer in women. Am. J. Clin. Nutr. 2008, 87, 734-743. [CrossRef]

49. Lin, J.; Lee, I.M.; Song, Y.; Cook, N.R.; Selhub, J.; Manson, J.E.; Buring, J.E.; Zhang, S.M. Plasma homocysteine and cysteine and risk of breast cancer in women. Cancer Res. 2010, 70, 2397-2405. [CrossRef] [PubMed]

50. Kim, S.J.; Zuchniak, A.; Sohn, K.J.; Lubinski, J.; Demsky, R.; Eisen, A.; Akbari, M.R.; Kim, Y.I.; Narod, S.A.; Kotsopoulos, J. Plasma folate, vitamin b-6, and vitamin b-12 and breast cancer risk in brca1- and brca2-mutation carriers: A prospective study. Am. J. Clin. Nutr. 2016, 104, 671-677. [CrossRef]

51. Houghton, S.C.; Eliassen, A.H.; Zhang, S.M.; Selhub, J.; Rosner, B.A.; Willett, W.C.; Hankinson, S.E. Plasma b-vitamins and one-carbon metabolites and the risk of breast cancer in younger women. Breast Cancer Res. Treat. 2019, 176, 191-203. [CrossRef]

52. Llaverias, G.; Danilo, C.; Mercier, I.; Daumer, K.; Capozza, F.; Williams, T.M.; Sotgia, F.; Lisanti, M.P.; Frank, P.G. Role of cholesterol in the development and progression of breast cancer. Am. J. Pathol. 2011, 178, 402-412. [CrossRef]

53. Wald, N.; Boreham, J.; Bailey, A. Serum retinol and subsequent risk of cancer. Br. J. Cancer 1986, 54, 957-961. [CrossRef] [PubMed]

54. Cham, B.E.; Smith, J.L.; Colquhoun, D.M. Correlations between cholesterol, vitamin e, and vitamin k1 in serum: Paradoxical relationships to established epidemiological risk factors for cardiovascular disease. Clin. Chem. 1998, 44, 1753-1755. [CrossRef] [PubMed]

55. Mangiarotti, R.; Danova, M.; Alberici, R.; Pellicciari, C. All-trans retinoic acid (atra)-induced apoptosis is preceded by g1 arrest in human mcf-7 breast cancer cells. Br. J. Cancer 1998, 77, 186-191. [CrossRef] [PubMed]

56. Arisi, M.F.; Starker, R.A.; Addya, S.; Huang, Y.; Fernandez, S.V. All trans-retinoic acid (atra) induces re-differentiation of early transformed breast epithelial cells. Int. J. Oncol. 2014, 44, 1831-1842. [CrossRef]

57. Wu, M.J.; Kim, M.R.; Chen, Y.S.; Yang, J.Y.; Chang, C.J. Retinoic acid directs breast cancer cell state changes through regulation of tet2-pkczeta pathway. Oncogene 2017, 36, 3193-3206. [CrossRef]

58. Ramaswamy, G.; Krishnamoorthy, L. Serum carotene, vitamin a, and vitamin c levels in breast cancer and cancer of the uterine cervix. Nutr. Cancer 1996, 25, 173-177. [CrossRef]

59. Zhang, X.; Harbeck, N.; Jeschke, U.; Doisneau-Sixou, S. Influence of vitamin D signaling on hormone receptor status and her2 expression in breast cancer. J. Cancer Res. Clin. Oncol. 2017, 143, 1107-1122. [CrossRef]

60. Deeb, K.K.; Trump, D.L.; Johnson, C.S. Vitamin D signalling pathways in cancer: Potential for anticancer therapeutics. Nat. Rev. Cancer 2007, 7, 684-700. [CrossRef] 
61. Stabler, S.P. Clinical practice. Vitamin b12 deficiency. N. Engl. J. Med. 2013, 368, 149-160. [CrossRef]

62. Sellers, T.A.; Vierkant, R.A.; Cerhan, J.R.; Gapstur, S.M.; Vachon, C.M.; Olson, J.E.; Pankratz, V.S.; Kushi, L.H.; Folsom, A.R. Interaction of dietary folate intake, alcohol, and risk of hormone receptor-defined breast cancer in a prospective study of postmenopausal women. Cancer Epidemiol. Prev. Biomark. 2002, 11, 1104-1107.

63. Gomes, A.P.; Ilter, D.; Low, V.; Endress, J.E.; Fernández-García, J.; Rosenzweig, A.; Schild, T.; Broekaert, D.; Ahmed, A.; Planque, M.; et al. Age-induced accumulation of methylmalonic acid promotes tumour progression. Nature 2020, 585, 283-287. [CrossRef] [PubMed]

64. Krishnan, A.V.; Swami, S.; Feldman, D. Vitamin D and breast cancer: Inhibition of estrogen synthesis and signaling. J. Steroid Biochem. Mol. Biol. 2010, 121, 343-348. [CrossRef] [PubMed]

65. Santos-Martinez, N.; Diaz, L.; Ordaz-Rosado, D.; Garcia-Quiroz, J.; Barrera, D.; Avila, E.; Halhali, A.; Medina-Franco, H.; Ibarra-Sanchez, M.J.; Esparza-Lopez, J.; et al. Calcitriol restores antiestrogen responsiveness in estrogen receptor negative breast cancer cells: A potential new therapeutic approach. BMC Cancer 2014, 14, 230. [CrossRef] [PubMed]

66. Cham, B.E.; Smith, J.L.; Colquhoun, D.M. Interdependence of serum concentrations of vitamin k1, vitamin E, lipids, apolipoprotein a1, and apolipoprotein b: Importance in assessing vitamin status. Clin. Chim. Acta Int. J. Clin. Chem. 1999, 287, 45-57. [CrossRef]

(C) 2020 by the authors. Licensee MDPI, Basel, Switzerland. This article is an open access article distributed under the terms and conditions of the Creative Commons Attribution (CC BY) license (http://creativecommons.org/licenses/by/4.0/). 